\title{
Studi Pengaruh Arus Polimerisasi terhadap Konduktivitas Listrik Polianilin yang Disintesis dengan Metode Galvanostatik
}

\author{
Diah Hari Kusumawati, ${ }^{*}$ Woro Setyarsih, dan Nugrahany Primary Putri \\ Jurusan Fsika-FMIPA, Universitas Negeri Surabaya, \\ Jl. Ketintang, Surabaya 60231
}

\begin{abstract}
Intisari
Sintesis polianilin dapat dilakukan secara elektrokimia dengan metode galvanostatik menggunakan rangkaian elektropolimerisasi galvanostatik yang terdiri dari sumber arus, tegangan, elektroda karbon sebagai elektroda kerja dan nikel sebagai elektroda mitra. Polianilin disintesis dalam sel elektrokimia yang terdiri dari larutan $\mathrm{HCl}$ dan anilin. Dengan menggunakan parameter arus yang optimum diperoleh hasil polianilin dengan konduktivitas listrik yang optimum $\left(25 \mathrm{Scm}^{-1}\right)$ pada sumber arus $3 \mathrm{~mA}$ dengan konsentrasi $\mathrm{HCl} 3 \mathrm{M}$ dan konsentrasi anilin 1 M.

KATA KUNCI: polianilin, elektrokimia, galvanostatik, konduktivitas listrik
\end{abstract}

\section{PENDAHULUAN}

Polianilin merupakan salah satu jenis polimer konduktif yang memiliki beberapa keunggulan dibanding polimer konduktif lainnya. Diantara polimer konduktif, polianilin menempati kedudukan yang istimewa karena kaya akan aspek ilmiah dan luas potensi aplikasinya seperti baterai sekunder, sensor, LED dan bidang optoelektronik lainnya [1]. Selain itu ditinjau dari aspek kestabilan di udara bahan polimer konduktif dari polianilin memiliki kestabilan yang paling baik di antara bahan polimer yang selama ini dikenal. Faktor inilah yang memungkinkan polianilin sebagai bahan berpotensi tinggi untuk produksi komersil. [2]

Polianilin dapat disintesis secara elektrokimia menghasilkan produk dalam bentuk film atau sintesis secara kimia akan menghasilkan polianilin dalam bentuk bubuk. Di antara teknik elektrokimia, metode galvanostatik merupakan salah satu metode elektropolimerisasi dimana proses doping terjadi bersamaan dengan polimerisasi. Selain jenis proses sintesis, sifat polianilin juga dipengaruhi oleh parameter sintesis seperti konsentrasi monomer anilin, jenis dopan dan konsentrasi yang digunakan, lama waktu, arus dan tegangan polimerisasi. Dengan parameter sintesis yang optimum, akan didapatkan polianilin dengan nilai konduktivitas listrik yang maksimum. Penelitian yang dilakukan sebelumnya [2] telah memperlihatkan pengaruh parameter konsentrasi anilin, $\mathrm{HCl}$ dan arus sintesis serta pemakaian elektroda kerja yang bervariasi dengan elektroda kerja yang digunakan adalah $\mathrm{Ag} / \mathrm{AgCl}$ telah dihasilkan kondisi optimum untuk sintesis ini adalah pada konsentrasi anilin dan $\mathrm{HCl}$ adalah $1 \mathrm{M}$ dan $3 \mathrm{M}$ (pada penelitian ini konsentrasi $\mathrm{HCl}$ dan anilin mengacu pada pustaka [2] arus sintesis $2 \mathrm{~mA}$ dan elektroda kerjanya adalah kar-

*E-MAIL:



Gambar 1: Struktur polianilin secara umum dalam bentuk basa

bon.

Pada penelitian ini digunakan konsentrasi monomer anilin $1 \mathrm{M}$ dan $\mathrm{HCl} 3 \mathrm{M}$ yang akan disintesis pada arus tertentu, sehingga diharapkan akan dapat diketahui pengaruh arus terhadap nilai konduktivitas listrik dari polianilin serta sifat fisika-kimia dengan spektroskopi FTIR dan UV-Vis.

Polianilin adalah molekul besar yang dibangun oleh pengulangan kesatuan kimia kecil dan sederhana yang disebut monomer anilin $\left(\mathrm{C}_{6} \mathrm{H}_{5} \mathrm{NH}_{2}\right)$ yang berikatan kovalen [3]. Penggabungan monomer-monomer anilin akan membentuk cincin-cincin benzoid (B) dan kuinoid (Q) yang dihubungkan satu dengan lainnya oleh atom nitrogen $(\mathrm{N})$ melalui ikatan amin dan ikatan imin. Secara umum struktur kimia polianilin dalam keadaan basa dapat ditulis sebagai ditunjukkan Gambar 1. Struktur polianilin yang terlihat pada Gambar 1 adalah polianilin yang bersifat isolator. Struktur tersebut tersusun dari dua gugus yaitu gugus tereduksi dan gugus teroksidasi.

Pada struktur polianilin dalam bentuk basa indeks y menyatakan tingkat oksidasi dari basa polianilin yang nilainya berkisar dari 0 sampai $1(0 \leq \mathrm{y} \leq 1)$. Besarnya nilai y yang berbeda akan memberikan struktur polianilin yang berbeda pula. Bila nilai $\mathrm{y}=0$ akan menghasilkan polianilin dalam bentuk basa pernigranilin, bernilai $\mathrm{y}=0,5$ berbentuk basa emeraldin, bernilai y $=1$ berbentuk basa leukoemeraldin, seperti ditunjukkan Gambar 2.

Ketiga bentuk oksidasi polianilin tersebut bersifat isolator. Dan sejauh ini hanya basa emeraldin yang dapat dibuat konduktif dengan cara protonasi, yang nantinya akan menghasilkan polianilin berbentuk garam emeraldin dengan struktur seperti Gambar 3. 


$$
\left[+\bigcirc-\overline{\mathrm{N}}=\langle\overline{-}=\overline{\mathbf{N}})(-\mathrm{O}-\overline{\mathbf{N}}=\langle\overline{\mathrm{N}}-\rangle]_{0}\right.
$$

(a)<smiles>Cc1ccc(Nc2ccc(N=Nc3ccc(N=Cc4ccc(Nc5ccc(N)cc5)cc4)cc3)cc2)cc1</smiles>

(b)

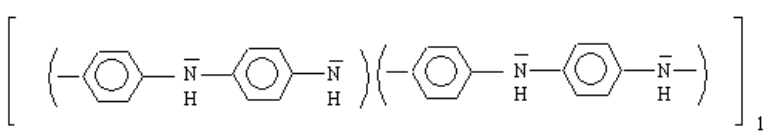

(c)

Gambar 2: Struktur polianilin berbentuk basa (a). pernigranilin, (b). emeraldin, (c). leukoemeraldin



Gambar 3: Struktur garam emeraldin

Polianilin bentuk basa emeraldin dapat dibuat konduktif dengan memberi perlakuan asam yang menghasilkan garam emeraldin. Garam emeraldin diperoleh melalui protonasi atom nitrogen yang berikatan imin dengan cincin kuinoid dari gugus teroksidasi dalam basa emeraldin. Proses protonasi ini menghasilkan cacat rantai dalam bentuk pasangan dikation dan dopan $\mathrm{A}^{-}$, yang diawali rumus lambang [(-B-NH$\left.\mathrm{B}-\mathrm{NH}-)\left(-\mathrm{B}-\mathrm{NH}^{+}=\mathrm{Q}=\mathrm{NH}^{+}-\right)\left(2 \mathrm{~A}^{+}\right)\right]_{n}$. Anion $\mathrm{A}^{-}$yang berasal dari bahan elektrolit (seperti ion $\mathrm{Cl}^{-}, \mathrm{H}_{2} \mathrm{SO}_{4}^{-}, \mathrm{BF}_{4}^{-}$ $\mathrm{dsb}$ ) masuk ke dalam polimer dan terikat secara coulomb dengan kation yang muncul pada rantai. Dikation ini dalam bahasan zat padat disebut bipolaron. Masuknya dopan melalui protonasi merupakan keunikan tersendiri yang tidak terdapat pada polimer konduktif lain. Dalam proses ini, jumlah elektron di dalam rantai tidak berubah, sedangkan proses doping polimer lainnya disertai perubahan jumlah elektron pada rantai polimer.

Metode elektrokimia adalah metode yang didasarkan pada reaksi redoks, yakni gabungan dari reaksi reduksi dan oksidasi, yang berlangsung pada elektroda yang sama/berbeda dalam suatu sistem elektrokimia. Sistem elektrokimia meliputi sel elektrokimia dan reaksi elektrokimia. Sel elektrokimia yang menghasilkan listrik karena terjadinya reaksi spontan di dalamnya disebut sel galvani. Sedangkan sel elektrokimia di mana reaksi tak-spontan terjadi di dalamnya disebut sel elektrolisis. Peralatan dasar dari sel elektrokimia adalah dua elektroda, umumnya konduktor logam yang dicelupkan ke dalam elektrolit konduktor ion (yang dapat berupa larutan maupun cairan) dan sumber arus. Karena didasarkan pada reaksi redoks, pereaksi utama yang berperan dalam metode ini adalah elektron yang dipasok dari suatu sumber listrik. Sesuai dengan reaksi yang berlangsung, elek-



Gambar 4: Rangkaian instrumen elektropolimerisasi elektrokimia

troda dalam suatu sistem elektrokimia dapat dibedakan menjadi katoda, yakni elektroda di mana reaksi reduksi (reaksi katodik) berlangsung dan anoda di mana reaksi oksidasi (reaksi anodik) berlangsung.

\section{METODE PENELITIAN}

Pada penelitian ini diperlukan preparasi bahan mencakup larutan monomer anilin pro analisis dengan konsentrasi $1 \mathrm{M}$ dalam $30 \mathrm{ml}$ asetonitril, larutan $\mathrm{HCl} 3 \mathrm{M}$ dalam $60 \mathrm{ml} \mathrm{H}_{2} \mathrm{O}$. Untuk mempelajari pengaruh arus sintesis terhadap hasil yang diperoleh, polianilin disintesis secara elektrokimia didalam sel yang berisi $60 \mathrm{ml} \mathrm{HCl} \mathrm{3M}$ monomer anilin 1M dengan menggunakan dua buah elektroda. Elektroda kerja (anoda) yang digunakan adalah karbon sedangkan elektroda mitra (katoda) adalah nikel. Arus yang digunakan yaitu $1 \mathrm{~mA}, 2 \mathrm{~mA}$, $3 \mathrm{~mA}, 4 \mathrm{~mA}$ dan $5 \mathrm{~mA}$.

Untuk pengukuran konduktivitas polianilin dilakukan dengan metode four point probe, sampel polianilin diletakkan pada kaca preparat yang berbentuk persegi panjang dengan lebar $\ell=1 \mathrm{~cm}$, tebal $\mathrm{t}=0,025 \mathrm{~cm}$ dengan jarak antar probe $\mathrm{d}$ $=0,1 \mathrm{~mm}$. Konduktivitas diperoleh dengan melalui konversi sederhana yaitu

$$
\sigma=\frac{i}{V} \frac{\ell}{d t}
$$

dengan i dan $\mathrm{V}$ adalah arus yang diberikan pada bahan dan potensial probe ke-2 dan -3 .

\section{HASIL DAN PEMBAHASAN}

Spektrum pada Gambar 5 dan Gambar 6 memperlihatkan puncak-puncak utama sekitar $1560 \mathrm{~cm}^{-1}, 1480 \mathrm{~cm}^{-1}$, adalah 




(a)

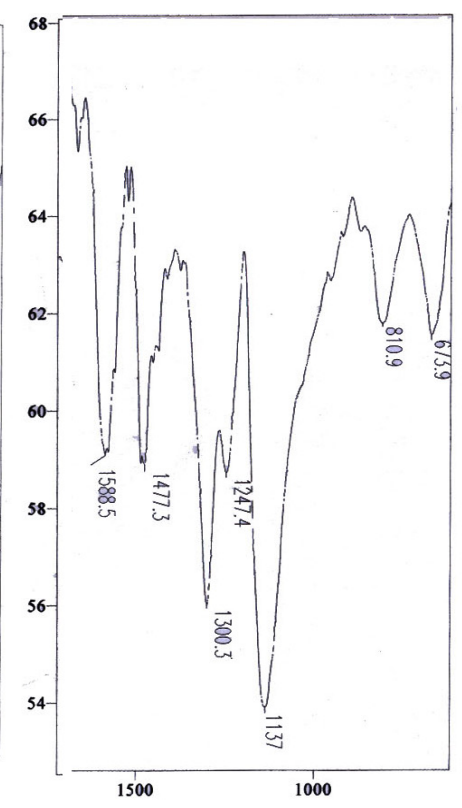

(b)



(c)

Gambar 5: FTIR dengan parameter arus (a). $2 \mathrm{~mA}$ (b). $3 \mathrm{~mA}$ dan (c). $4 \mathrm{~mA}$

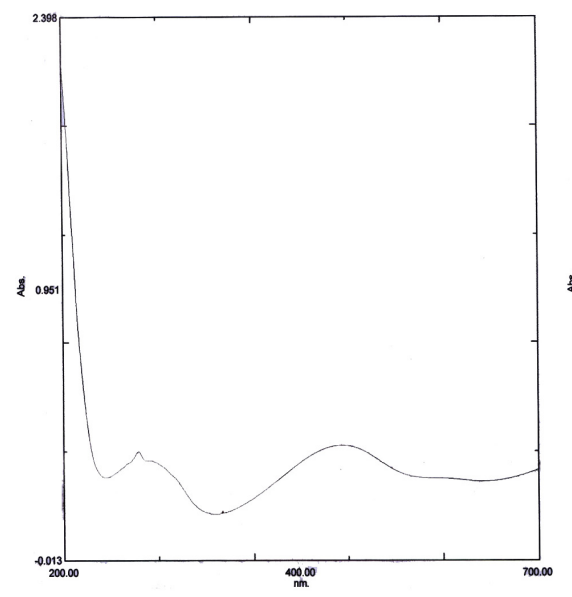

(a)

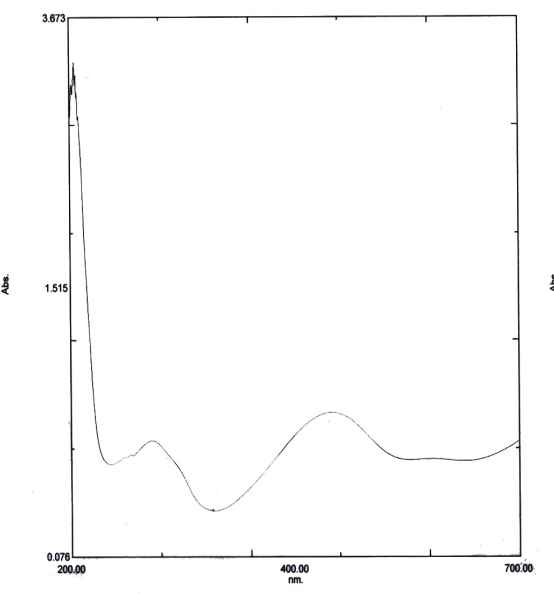

(b)

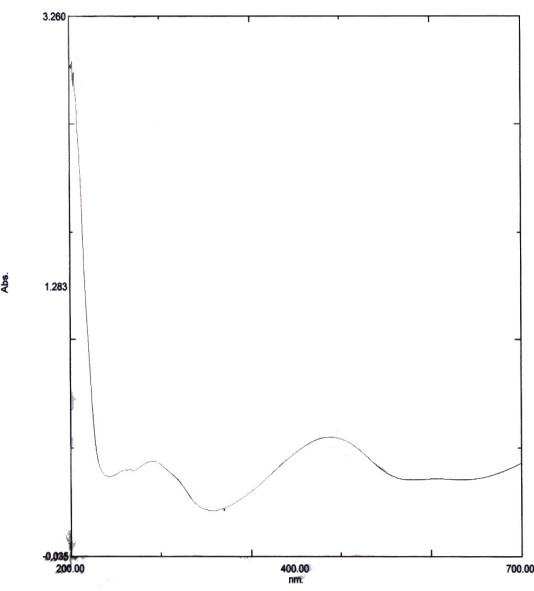

(c)

Gambar 6: UV-Vis dengan parameter arus (a) $2 \mathrm{~mA}$ (b) $3 \mathrm{~mA}$ dan (c) $4 \mathrm{~mA}$

sinyal modus vibrasi breathing $\mathrm{C}=\mathrm{C}$ dari cincin $\mathrm{Q}$ dan $\mathrm{B}$. Pita vibrasi lain adalah stretching $\mathrm{C}-\mathrm{N}$ pada $1300 \mathrm{~cm}^{-1}, 1250$ $\mathrm{cm}^{-1}$ dan vibrasi bendhing $\mathrm{C}-\mathrm{H}$ pada $1130 \mathrm{~cm}^{-1}$ dan 810 $\mathrm{cm}^{-1}$. Bentuk spektrum polianilin ini tidak berubah dengan bertambahnya waktu dan arus sintesis tetapi terlihat adanya pergeseran puncak pita Q sekitar $20 \mathrm{~cm}^{-1}$ dan pita B sekitar $10 \mathrm{~cm}^{-1}$. hasil ini mirip dengan hasil penelitian sebelumnya $[4,5]$.

Gambar 6 adalah spektrum UV-Vis dari sampel yang disintesis dengan parameter arus yang bervariasi. Pada masingmasing spektrum muncul dua pita spektrum yaitu sekitar 490 $\mathrm{nm}(2,5 \mathrm{eV})$ yang melebar sekitar $725 \mathrm{~nm}(1,7 \mathrm{eV})$, disekitar $300 \mathrm{~nm}(3,9 \mathrm{eV})$ dan $880 \mathrm{~nm}-1100 \mathrm{~nm}(1,1 \mathrm{eV}-1,4 \mathrm{eV})$. Puncak pada $1,1 \mathrm{eV}-1,4 \mathrm{eV}$ ini tidak tampak pada Gambar dikare- nakan keterbatasan alat yang tidak mampu merekam dengan baik pada panjang gelombang diatas $800 \mathrm{~nm}$. Pola spektrum ini bersesuaian dengan penelitian sebelumnya [4, 5]. Dari hasil pembacaan UV-Vis dapat digambarkan transisi elektronik seperti Gambar 7.

Dari hasil pengukuran konduktivitas listrik, terlihat adanya variasi yang cukup peka terhadap waktu polimerisasi. Hasil pengukuran konduktivitas tersebut mengisyaratkan adanya suatu kondisi sintesis yang optimum untuk menghasilkan polianilin dengan konduktivitas tertinggi. Hal ini berkaitan dengan adanya kenaikan arus yang sangat menentukan sifat konduktivitas polianilin yang dihasilkan, dimana kenaikan arus tersebut hingga harga tertentu menghasilkan kenaikan konduktivitas, namun kenaikan selanjutnya akan menurunkan 


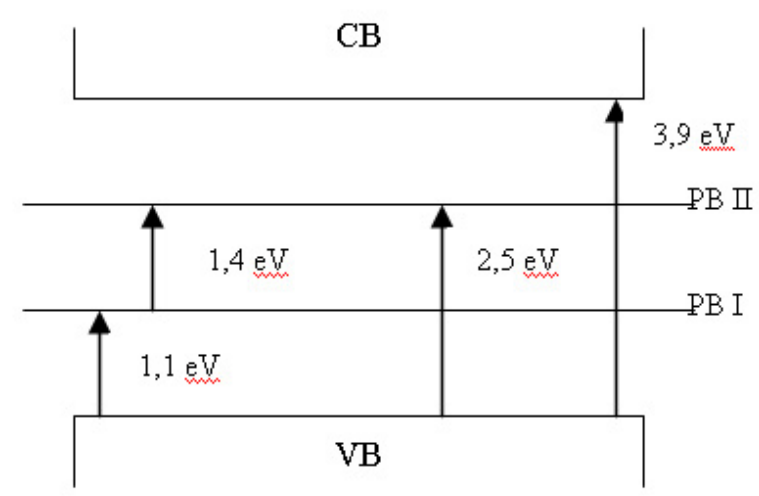

Gambar 7: Transisi elektronik dalam polianilin dari hasil UV-Vis



Gambar 8: Grafik hubungan antara konduktivitas listrik polianilin dengan parameter arus sintesis

konduktivitas (Gambar 8). Kebergantungan ini memperlihatkan bahwa arus sintesis juga akan mempengaruhi proses oksidasi pembentukan cacat (proses doping) selama sintesis.
Konduktivitas polianilin mengalami kecenderungan kenaikan pada kondisi sintesis arus $3 \mathrm{~mA}$ (dengan konduktivitas maksimum $25 \mathrm{Scm}^{-1}$ ). Pada kondisi ini polianilin yang diperoleh dalam bentuk garam emeraldin. Garam emeraldin terbentuk akibat terjadi proses doping melalui protonasi pada rantai polimer polianilin. Cacat rantai yang terbentuk akibat protonasi ini berupa pasangan dikation atau sering disebut bipolaron yang berperan sebagai pembawa muatan. Keberadaan bipolaron ini dalam rantai polianilin akan membuat polianilin menjadi polimer konduktif.

\section{SIMPULAN}

Dalam penelitian ini telah dilakukan proses sintesis polianilin secara elektrokimia dengan metode galvanostatik dan telah didapatkan parameter-parameter sintesis optimum untuk menghasilkan polianilin dengan kecenderungan kenaikan konduktivitas diperoleh pada kondisi arus $3 \mathrm{~mA}$ (dengan nilai konduktivitas listrik maksimum $25 \mathrm{Scm}^{-1}$ ).

Bentuk spektrum FTIR dan UV-Vis yang dihasilkan dari polimerisasi ini menunjukkan bahwa hasil sintesis ini benar polianilin. Spektrum yang dihasilkan dari pengujian FTIR memperlihatkan penyerapan spektrum ini sekitar $1600 \mathrm{~cm}^{-1}$ dan $1500 \mathrm{~cm}^{-1}$ untuk sinyal modus breathing $\mathrm{C}=\mathrm{C}$ dari cincin $\mathrm{Q}$ dan B. vibrasi lain adalah stretching C-N $1300 \mathrm{~cm}^{-1}, 1250$ $\mathrm{cm}^{-1}$ dan vibrasi bending $\mathrm{C}-\mathrm{H} 1130 \mathrm{~cm}^{-1}$ dan $810 \mathrm{~cm}^{-1}$. Sedangkan hasil pengujian UV-Vis terjadi puncak-puncak penyerapan yang menyebabkan terjadinya transisi elektron yaitu pada $1,1 \mathrm{eV}, 1,4 \mathrm{eV}, 2,5 \mathrm{eV}$ dan 3,9 eV.

Nilai konduktivitas listrik polianilin sangat dipengaruhi arus sintesis. Semakin besar arus sintesis menaikkan konduktivitas listrik polianilin. Tetapi pada peningkatan konsentrasi selanjutnya mengakibatkan penurunan konduktivitas listrik polianilin.
[1] A. Malinaukas, J. Malinauskiene, and A. Rawanavicius, Nanotechnology 16, R51 - R62 (2005).

[2] Kholik, Isa Abdul, Dkk., Optimasi Sintesis Polianilin secara Elektrokimia, Jurnal Penelitian, FMIPA-Universitas Jember, 2002.

[3] Kusumawati, D.H., Analisis Pengaruh Pemanasan terhadap Konduktivitas Listrik Polianilin dengan Doping Asam Klorida,
Laporan Tugas Akhir, Fisika, FMIPA-ITS, Surabaya, 1995.

[4] Hidayat, Rachmat, Elektropolimerisasi dan Doping Polianilin serta Pengkajian Pengaruh Parameter Sintesisnya, Laporan Tugas Akhir, ITB, Bandung, 1993.

[5] Fessenden, Ralp. J., Kimia Organik ,Jilid I, diterjemahkan oleh Alaytius H.(Erlangga,Jakarta, 1986). 